\title{
A Case Report on a Rare Cervical Polyp
}

\author{
Ayman Aboda*, Angela Wu, Kimberly Sleeman and Brian McCully \\ Department of Obstetrics \& Gynaecology, Mildura Public Base Hospital, Australia
}

Submission: February 14, 2022; Published: February 23, 2022

*Corresponding author: Dr Ayman Aboda Department of Obstetrics \& Gynaecology, Mildura Public Base Hospital, Mildura 3500, Victoria, Australia

\begin{abstract}
Background: Giant cervical polyps are rare. They are commonly asymptomatic and diagnosed incidentally on pelvic examination.

Case: This is a 59-year-old multiparous who had a giant cervical polyp diagnosed on speculum examination after presenting to her general practitioner reporting symptoms of pelvic pressure and heaviness. The polyp was successfully resected with hysteroscopy.
\end{abstract}

Conclusion: A giant cervical polyp in a multiparous female which was successfully resected during hysteroscopy.

Keywords: Giant cervical polyps; Gynecologic pelvic examination; Hysteroscopy; Submucous leiomyoma; Pelvic pressure; Vaginal resection

\section{Introduction}

Giant cervical polyps are rarely seen in routine clinical practice. They are defined as being greater than $4 \mathrm{~cm}$ in size [1]. Giant cervical polyps protruding outside the vaginal canal can cause diagnostic confusion. They are rarely encountered in gynecologic practice. They are uncommon though can appear in all age groups and in both nulliparous and multiparous women. The incidence is $4-10 \%$. They are most commonly asymptomatic, discovered incidentally at routine gynecologic pelvic examination. Cervical polyps originate most commonly from the ectocervix and are called cervical polyps. More rarely, they arise from the endocervical canal and are called endocervical polyps. Most are less than $2 \mathrm{~cm}$ in diameter.

\section{Case Presentation}

This case report is about a giant cervical polyp in a 59-yearold female, gravida 4 para 3 with three previous normal vaginal deliveries. Her menarche was at the age of 16 and her menstrual interval was 28-30 days with a duration of 3 days. She was menopausal at the age of 48 . She became aware of a lump in her vagina 5-6 months prior to presentation to her general practitioner (GP). She reported no vaginal or post coital bleeding and had not been sexually active for some time. The sensation of the lump was most noted when both walking and standing however there were no concerns with bowel or urinary function. She never had cervical screening. She was otherwise in good health apart from hypertension not requiring medications. Her mother had ovarian cancer but there was no other significant family history.
Her GP noted a cervical polyp protruding from the cervix and extending to the introitus. Clear views of the cervix were not possible and cervical screening though attempted, could not be successfully completed. The patient was referred to our service. On speculum examination, a large polyp was again visualized and noted to obstruct clear views of the cervix. Differential diagnosis included cervical polyp or prolapsed fibroid. She was booked for diagnostic examination under anesthesia with hysteroscopy and vaginal resection if possible.

At the procedure, a polyp extending $5 \mathrm{~cm}$ beyond the external cervical os was noted, a pedicle was located within the endocervical canal. The cervix was dilated to Hagar number 10 followed by hysteroscopic resection with tissue sent to histopathology. Cervical screening test was completed at the same time. The patient recovered easily and was discharged safe and well the same day.

The histopathology reported a tissue measuring 50x35x25mm with no atypia, necrosis or significant mitotic activity. The conclusion was that the cervical polyp was a submucous leiomyoma. The cervical screening test was negative with recommendation for rescreening in five years.

\section{Discussion}

Giant cervical polyps are rare. In this case, the polyp was a fibroid or leiomyoma which had arisen from the endocervix. 


\section{Juniper Online Journal of Case Studies}

This is a rare presentation occurring in only $0.6 \%$ of cases where pathology has been identified.

Classification of fibroid is according to the involvement of uterine wall, being intramural, sub-serosa and transmural [2]. Cervical fibroids are grouped as type 8 , an additional category for leiomyomas not related to myometrium [2].

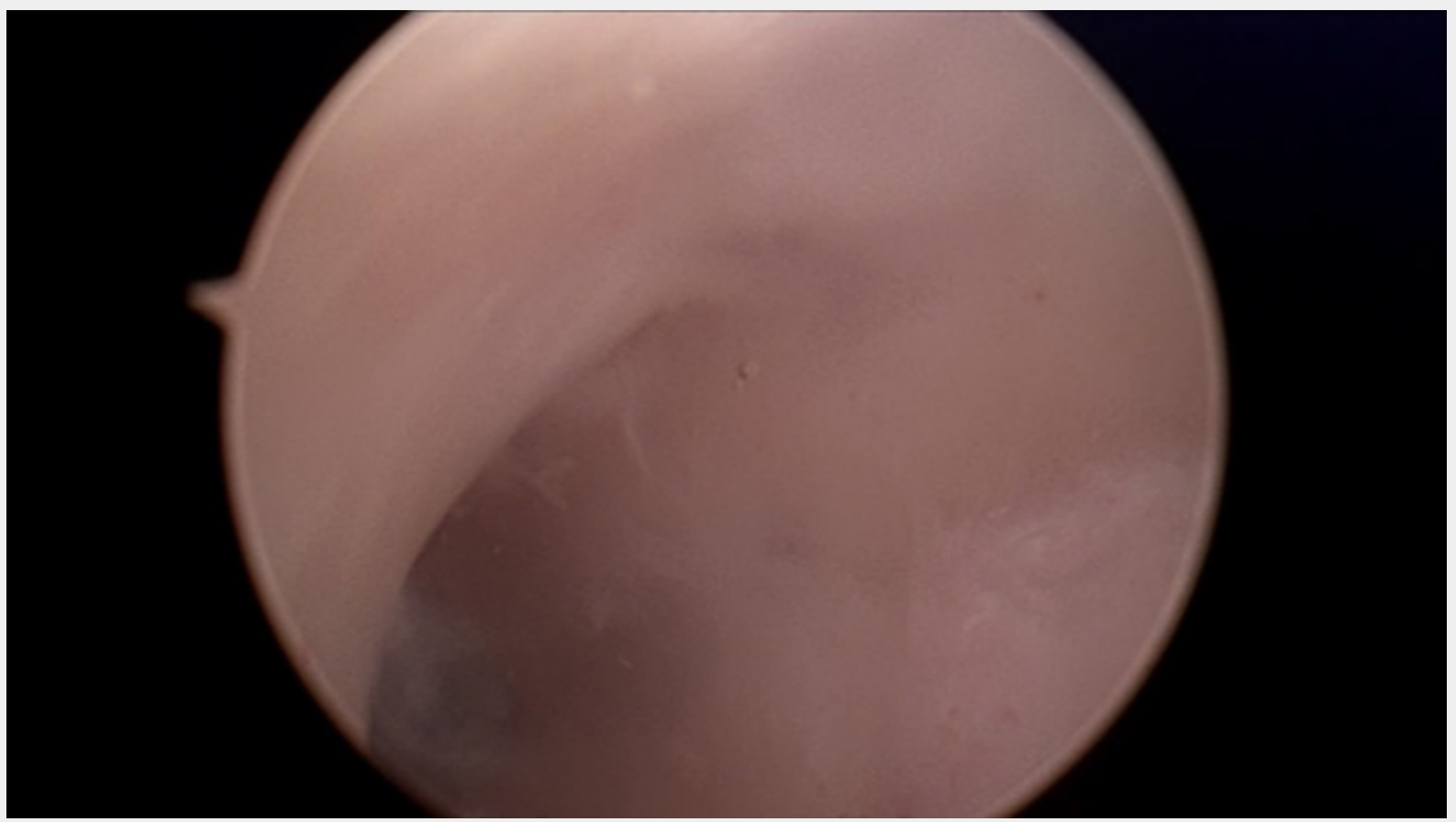

Figure 1: Right ostia on hysteroscopy.

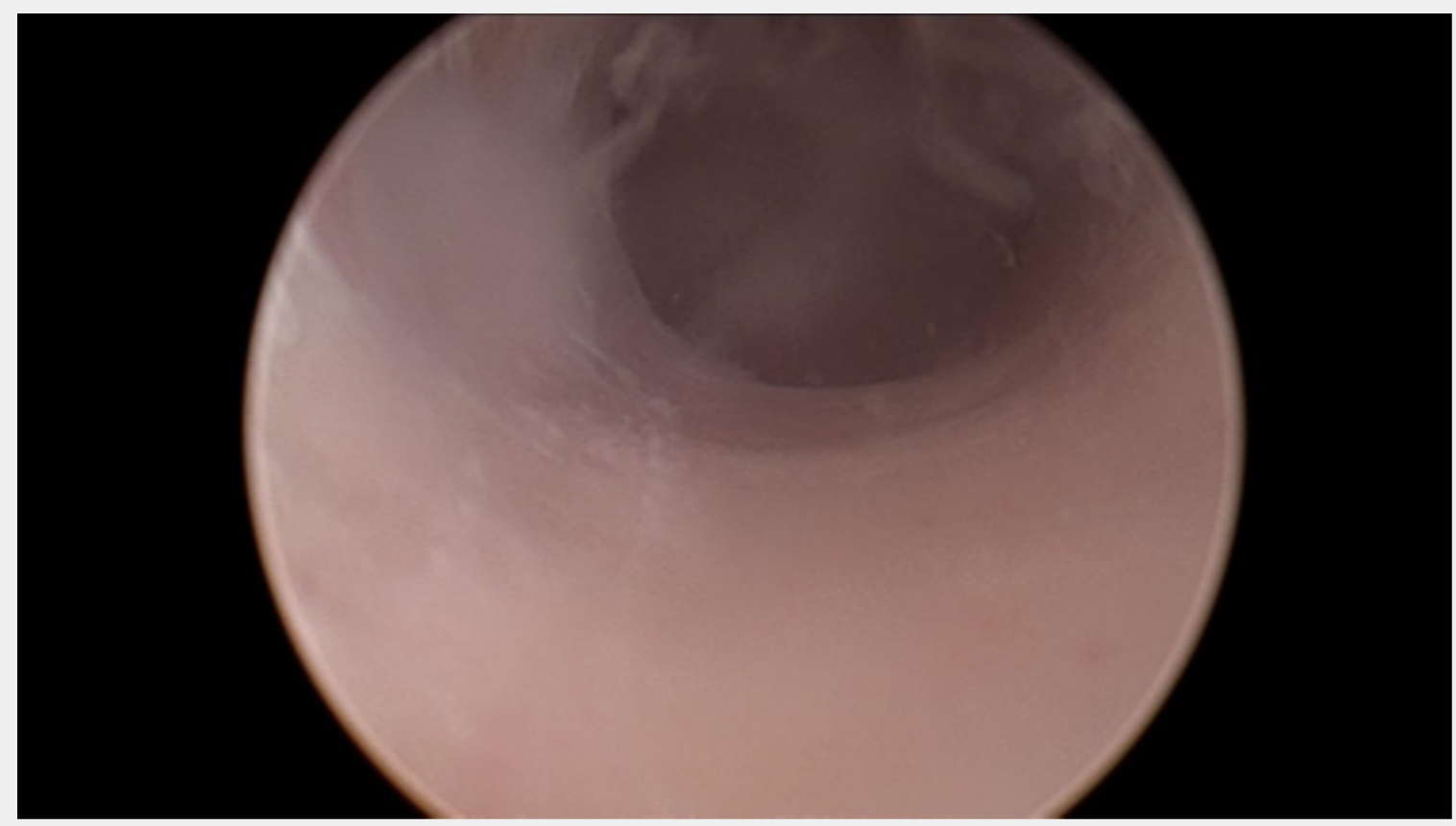

Figure 2: Left ostia on hysteroscopy. 


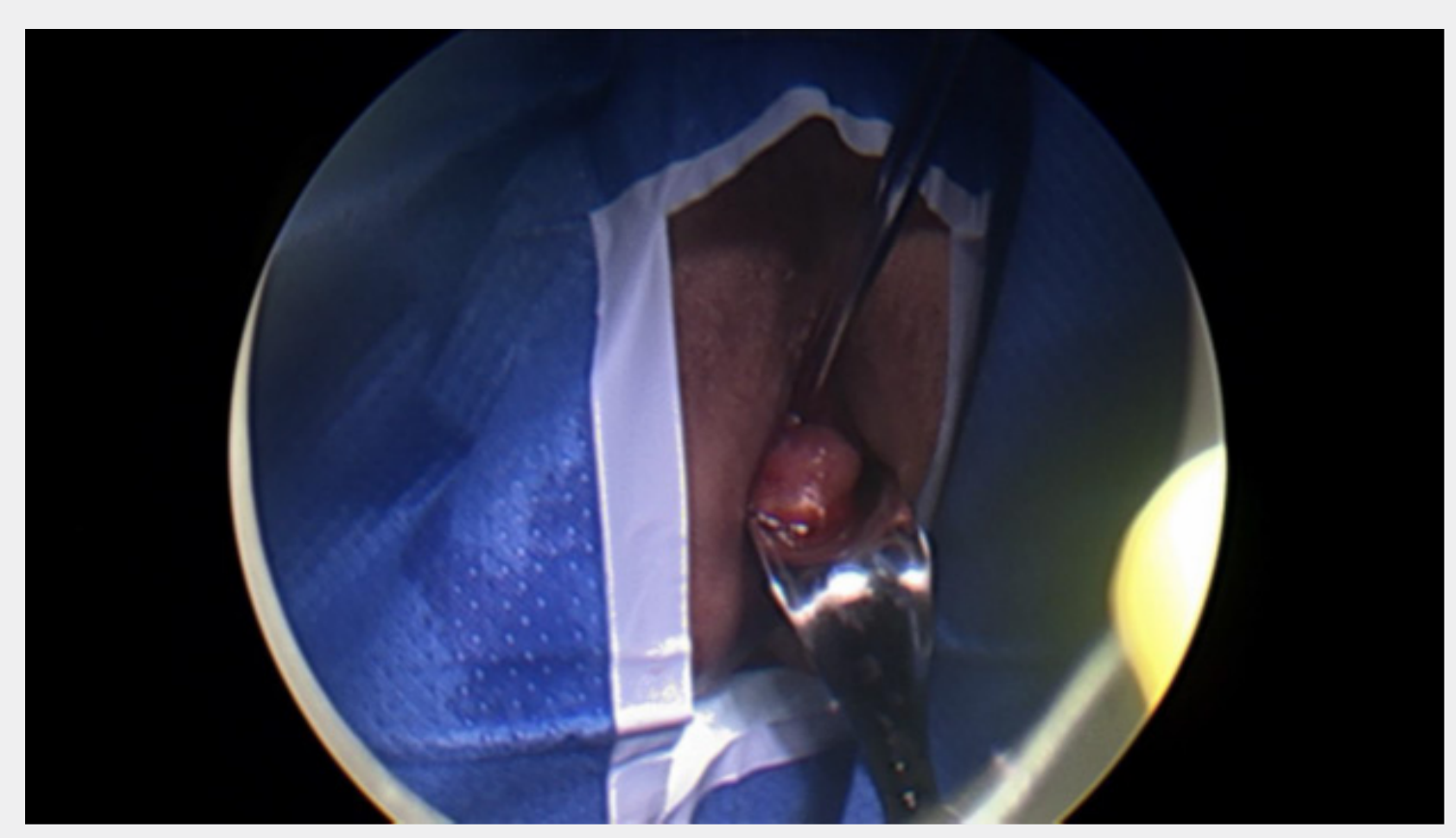

Figure 3: Giant cervical polyp.

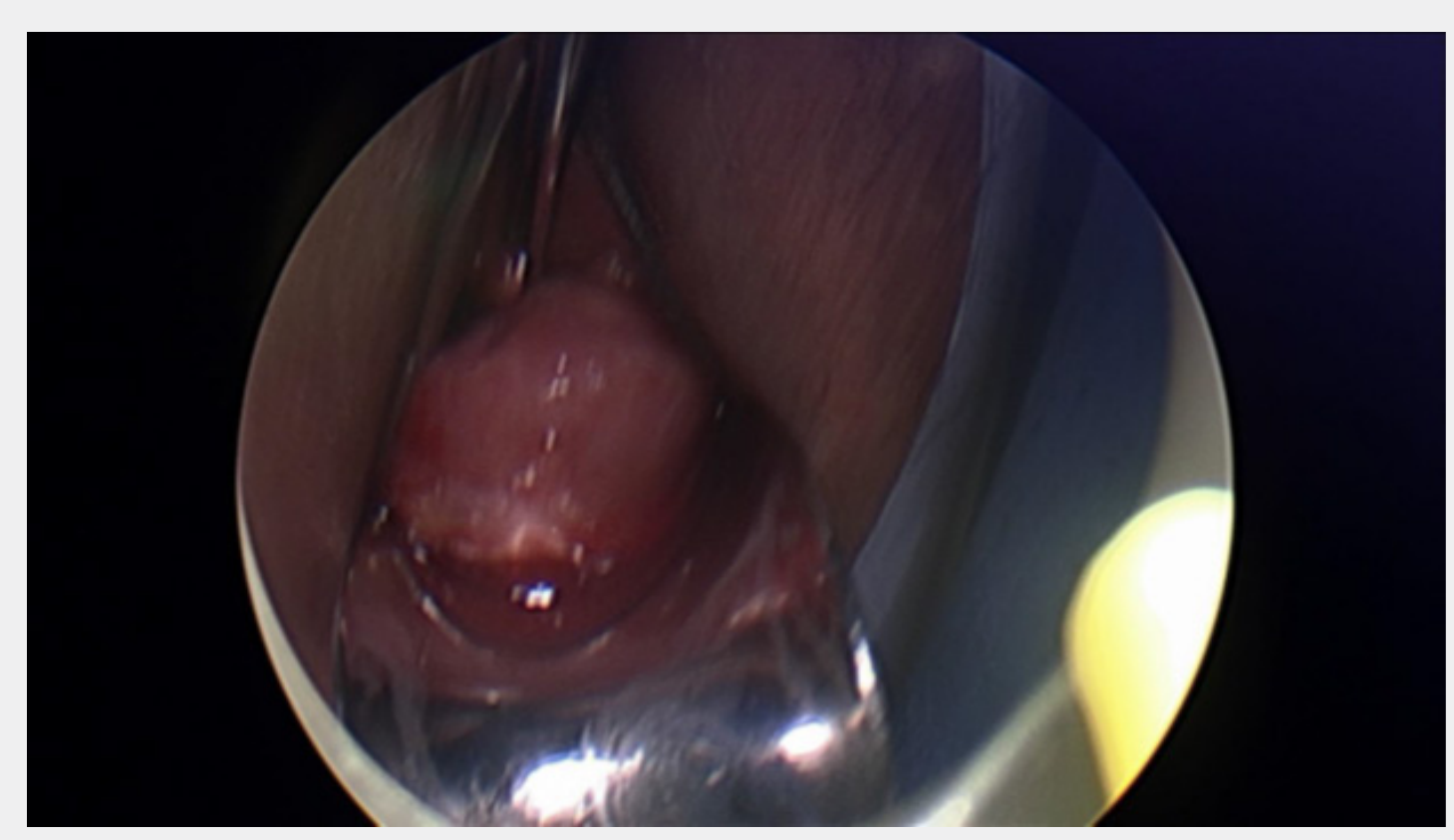

Figure 4: Giant cervical polyp.

Diagnosis of fibroid usually start with pelvic examination followed by confirmation on ultrasound which is the gold standard test [3]. MRI could be used to further assess the fibroids to provide information on size, vascularity, location in relation to endometrial cavity and serosa [3]. Hysteroscopy is used to differentiate myoma with polyps, and sometimes an endometrial biopsy is performed at the same time [3]. No radiological investigation was used in this case which is not common. The lesion in this case was intracervical which was found in $22 \%$ of the patients in a recently published systematic review [4]. 
Management of fibroid usually depends on symptoms and preference on fertility preservation. The above-mentioned systematic review on cervical leiomyoma showed that they are most commonly associated with symptoms of abnormal uterine bleeding (44\%), followed by volume-related symptoms (20\%) such as pressure or the sensation of a lump. Chronic pelvic or lower back pain $(14.6 \%)$ and chronic urinary complaints (11\%) may also occur [4]. Only $7.7 \%$ of the patients were asymptomatic [4]. The patient described in this case report presented with bulkrelated symptoms only with no other related concerns.

Medical management for symptom relief may include progesterone receptor modulators, tranexamic acid and gonadotropin-releasing hormone (GnRH) agonist [5]. These tend however to be limited by the duration of treatment, with symptoms often returning once intervention has ceased. Surgical treatment may be more successful in providing long term improvement. Procedures include myomectomy, embolization, hysterectomy and hysteroscopic myomectomy [5,6]. Most patients with cervical leiomyoma undergo surgical treatment (88\%) with myomectomy, hysterectomy or trachelectomy. In the case described, fertility preservation was not an issue. It was still important however to provide surgical management in the least provocative manner and thus safeguard against risk of iatrogenic morbidity. Hysteroscopic resection was thus successfully performed. There are no citations in the literature reporting similar success in patients presenting in this manner [4].

\section{Conclusion}

In conclusion, this was a case of a patient with finding of a large cervical fibroid with mass-related symptoms successfully treated with minimally intrusive, hysteroscopic resection.

\section{Data Availability}

Not applicable as this is a case report.

\section{Funding Statement}

The research did not receive specific fund but done as part of the employment of the authors, employer is Mildura Public Base Hospital.

\section{References}

1. Gothwal M, Singh P, Bharti JN, Yadav G, Solanki V (2019) Giant Cervical Angiomyomatous Polyp Masquerading Third-Degree Uterine Prolapse: A Rare Case with Review of Literature. Int J Appl Basic Med Res 9(4): 256-258.

2. Munro MG, Critchley HO, Broder MS, Fraser IS (2011) FIGO classification system (PALM-COEIN) for causes of abnormal uterine bleeding in nongravid women of reproductive age. Int J Gynaecol Obstet 113(1): 3-13.

3. Donnez J, Dolmans MM (2016) Uterine fibroid management: from the present to the future. Hum Reprod Update 22(6): 665-686.

4. Ferrari F, Forte S, Valenti G, Ardighieri L, Barra F, et al. (2021) Current Treatment Options for Cervical Leiomyomas: A Systematic Review of Literature. Medicina (Kaunas) 57(2): 92.

5. Stewart EA, Laughlin Tommaso SK, Catherino WH, Lalitkumar S, Gupta D, et al. (2016) Uterine fibroids. Nat Rev Dis Primers 2: 16043.

6. Vilos GA, Allaire C, Laberge PY, Leyland N (2015) The management of uterine leiomyomas. J Obstet Gynaecol Can 37(2): 157-178.

\section{Your next submission with Juniper Publishers} will reach you the below assets

- Quality Editorial service

- Swift Peer Review

- Reprints availability

- E-prints Service

- Manuscript Podcast for convenient understanding

- Global attainment for your research

- Manuscript accessibility in different formats ( Pdf, E-pub, Full Text, Audio)

- Unceasing customer service

\section{Track the below URL for one-step submission}

https://juniperpublishers.com/online-submission.php 